\title{
A Study on Current Situation and Development Strategies on Bilingual Teaching
}

\author{
Lizhi Kong and Suolan Liu * \\ Changzhou University, Jiangsu, China, 213164 \\ lan-liu@163.com \\ * The corresponding author
}

\section{Keywords: Bilingual Teaching; Measures; Effectiveness; Students; Teachers}

\begin{abstract}
In colleges and universities, bilingual teaching plays an important role in promoting students' international vision and employment opportunities. However, many difficulties are met in the process of implementing bilingual teaching, resulting in the failure of its development. How to effectively improve the current existing situation is the key problem of bilingual teaching reform in universities. Based on the analysis of the current situation from the perspective of students and teachers, we put forward several corresponding development strategies and measures for reference in this paper.
\end{abstract}

\section{Introduction}

With the process acceleration of economic globalization and the policy of deeply opening to outside world, higher requirements for cultivating international and senior professional talents are put forward. Bilingual teaching in colleges and universities is undoubtedly one of the most important ways to cultivate qualified personnel for meeting international demand. Since 2001, the Ministry of education has promulgated a series of guiding documents, which require colleges and universities to create conditions for public and professional courses teaching by using English or other foreign languages in the undergraduate education stage. Especially, in these fields of information technology, biotechnology, new materials technology, finance, law and other urgent needs for national development, bilingual teaching courses are required to reach $5 \%$ to $10 \%$ of all courses in three years. At present, in China the bilingual teaching language mainly includes Chinese and English. It is a new teaching mode for non language majors. Bilingual teaching becomes a hot topic in the reform of curriculum teaching in recent years.

Actually, bilingual teaching can take great boost to undergraduate education, which can be seen as is a revolution in the field of higher education. It requires the gradual transformation of teaching arrangements from foreign language points to professional knowledge points. From the traditional way of teaching and inculcating knowledge, the teaching of foreign languages is transferred to the way of studying the research methods and putting forward the problems which are adapted to the professional teaching, so that students can get the psychological atmosphere of the foreign language through self exploration. The goal of bilingual teaching is to pursue the long-term effect of the quality of talents, not to learn foreign language terminology or vocabulary. In the long run, bilingual teaching means to cultivate the students' ability to apply foreign languages, improve their ability to learn and acquire information, and enable students to continue to learn their professional knowledge after graduation, and to understand the frontier and the latest progress in the fields of domestic and foreign. Therefore, the implementation of bilingual teaching in colleges and universities is very important for students. However, for some reasons it is difficult to effectively implement bilingual teaching in public and professional courses in colleges and universities.

In this paper, we study and analyze the current situation of bilingual teaching and the main factors affecting the quality of bilingual teaching, and then put forward some corresponding measures for reference. 


\section{Current Situation of Bilingual Teaching}

The Shortage of Bilingual Teachers. Compared with top universities, the implementation of bilingual teaching in regular universities undoubtedly faces more difficulties. The biggest difficulty is that there is no qualified bilingual teaching staff. The extreme shortage of teachers is the bottleneck that hinders the development of bilingual teaching in these universities, including top universities. It is reported that the promotion rate of bilingual teaching in Beijing is only $10 \%$, while Shanghai has been exploring bilingual teaching since the last century, but it is still not popularized now. Bilingual teaching teachers in some top universities are less than 5\%. It can be seen that the lack of qualified teachers is a major factor in the promotion of bilingual teaching. To solve this problem, some universities put forward to arrange English teachers to teach professional courses. However, in professional courses' bilingual teaching, teachers are required not only to express and communicate freely in foreign languages, but also to have a wealth of professional knowledge. So, this method can't solve the problem fundamentally.

Students' Ability to Accept Course Content in Bilingual Teaching. The acceptance ability of students is one of the key factors in bilingual teaching. Students in regular universities usually do not have enough foreign language reserves and psychological preparation to receive bilingual teaching. In particular, some logically specialized courses are more difficult for students to receive and understand professional content than listening to their mother languages. In the past three years, the author has taught 《Pattern Recognition》 by using bilingual teaching for computer majors. However, after few times of the course we have to switch to Chinese teaching. Because this is a professional course for high demand of understanding. When students listen to teaching in Chinese, they all need some time to think about the content, let alone listen to the English lecture. Many students need to re-teach themselves after listening to the bilingual teaching because they do not understand the professional content. In this way, students feel that bilingual teaching is a great waste of time. They think that specialized courses have become professional English translation classes, and they don't know whether they are listening to English or listening to pattern recognition courses. Such a state of teaching brings great psychological pressure to both students and teachers.

Students' and Teachers' Attitudes to Bilingual Teaching. In the past three years, the authors have conducted a continuous questionnaire survey on the influencing factors of bilingual teaching to students of computer majors in changzhou university. Among the surveyed 273 students, the total number of graduate students was 86 . The pass rate of CET-4 is $97.07 \%$, and the pass rate of CET- 6 is $10.26 \%$. The results of the survey show that different groups have slightly different views on the influencing factors of bilingual teaching. Here we list the top four factors for reference including student's English proficiency, teacher's English proficiency, professional level and teaching method. The survey results are displayed in Fig. 1 One can see that for both undergraduates and postgraduates, more than 95\% students view teaching method as the most important factor. Teaching methods play a key role to teaching effectiveness. Good teaching methods can effectively arouse students' learning enthusiasm and get twice the result with half the effort. About $96.26 \%$ undergraduates think their English proficiency has great effect on learning and understanding compared to $26.74 \%$ of postgraduates.

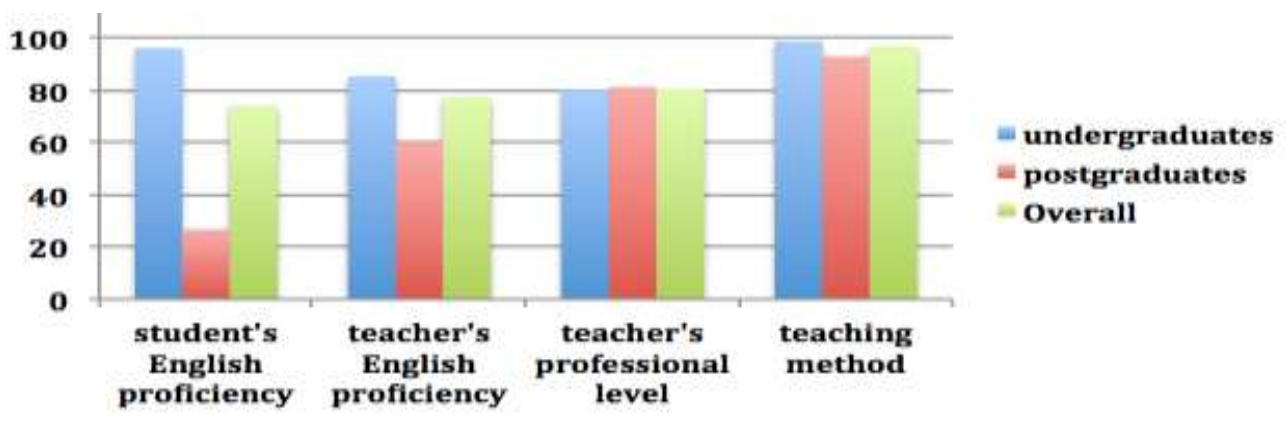

Figure 1. Finite Survey results on students' attitudes to main factors of bilingual teaching 
On the other hand, we surveyed the teachers who done bilingual teaching in the past five years. More than 80\% teachers thought that teacher's English proficiency was the most important factor in bilingual teaching and the primary difficulty in bilingual teaching reform. Then, there were other factors such as students, teaching materials, teaching methods and so on, which played minor influences.

\section{Several Suggestions on Bilingual Teaching}

Establishing Good Management and Incentive Mechanism for Bilingual Teaching. Bilingual teaching requires a lot of effort from teachers and students. For teachers, they spend a lot of time and energy in preparing bilingual teaching, therefore, universities should improve their class fees to confirm teachers' hard work. Teachers with bilingual teaching ability should be given priority in evaluating and hiring. Bilingual teaching can also be used as a performance indicator, which is directly linked to salary and position allowance, in order to mobilize the enthusiasm of teachers to carry out bilingual teaching. For students, under the influence of long term exam oriented education, some students are more concerned about the test scores, and do not care about the improvement of their ability for using foreign language. Therefore, the universities and the teachers should guide the students to understand the importance and significance of bilingual teaching. They should encourage them to overcome the difficulties encountered in the bilingual teaching, and make them understand that although it is difficult to listening and understanding the professional content in courses of bilingual teaching and should pay a lot of time after class. However, they will definitely improve the ability of applying foreign language and the ability to access foreign literature, and especially this will be a lifelong benefit. In addition, universities can appropriately improve the credits in bilingual teaching courses, so as to encourage students' learning enthusiasm.

Strengthening Teacher Training in Bilingual Teaching. Bilingual teaching has put forward higher requirements for both sides of the teaching and learning. Practical research has pointed out that as long as the teacher can express knowledge fluently, bilingual teaching courses can be carried out for the students with the English level four levels or above. Otherwise, if the teacher's English is limited, then we should set a higher demand for the language acceptability of the audience. Under such a requirement, at present teachers who are competent for bilingual teaching in domestic universities are still scarce. To solve this problem, on one hand colleges and universities can introduce overseas students, especially high level talents with doctorate degree, on the other hand, they should provide uninterrupted English training opportunities for existing teachers.

Improving Teaching Methods and Measures. Scientific teaching methods and teaching measures can overcome obstacles brought by language within a certain range and become the most accessible and convenient bridge linking teaching and learning. Therefore, when the efforts to improve English ability meet certain bottlenecks, the focus of teaching reform should be transferred to teaching methods and measures correspondingly. Such as carrying out questioning teaching or case teaching modes to make best use of the advantages and bypass the disadvantages of bilingual teaching.

\section{Conclusion}

As a new and innovative teaching mode in the information age, Bilingual teaching is adapt to the current trend of education international reform in China. It is based on the construction of high-quality educational resources and information-based learning environment, which puts forward new challenges and requirements for both students and teachers. In view of the current situation of bilingual teaching in China, we put forward several suggestions for reform to help to steadily break through the bottleneck of its development. It is hoped that it can effectively improve the efficiency and effect of bilingual teaching and provide a reference for the current reform and development of bilingual teaching in China. 


\section{Acknowledgements}

This work is supported by the project of Changzhou University (No.2015XSJ11 and No.CDGZ2016002) .

\section{References}

[1] M Shuai. Consideration on the teaching modes of bilingual education in colleges and universities in China [J]. Journal of hubei institute of education, 2005, 22 (2) :109-111.

[2] D Mavrikios, K Georgoulias, G Chryssolouris. The Teaching Factory Paradigm: Developments and Outlook [J]. Procedia Manufacturing. 2018, 23:1-8.

[3] L Luo, J Wang. Reflection on bilingual teaching in universities [J]. Theory and practice of education, 2004,9:59-61

[4] J Linhart. A field guide for teaching evolution in the social sciences [J]. Evolution and Human Behavior, 2018,39 (3): 257-268

[5] E Karen, B Etzkorn. Learning to teach online: Measuring the influence of faculty development training on teaching effectiveness through a TPACK lens [J]. The Internet and Higher Education. 2018, 38: 28-35

[6] S Sharma, A Ali, R Takhelmayum, R Nair. Co-teaching: Exploring an Alternative for Integrated Curriculum [J]. Journal of the National Medical Association, 2017,109(2): 93-97.

[7] X Jia, W Hu, F Cai. The influence of teaching methods on creative problem finding [J]. Thinking Skills and Creativity, 2017, 24: 86-94

[8] H Tatum, B Schwartz. Classroom participation and student-faculty interactions: does gender matter? Journal of High Education. 2013,84(6): 745-768.

[9] Michille. University teachers' innovative teaching behavior and the relationship between the innovative ability of college students Investigate [J]. Journal of teaching research, 2013, 15-18.

[10] S Liu, LKong. Research on the Relationship and measures of innovative ability between students and teachers, Advances in Computer Science Research, 2017, 59: 642-645 